\title{
Multiple Antipassives in Halkomelem Salish
}

\author{
DONNA B. GERDTS and THOMAS E. HUKARI
}

Simon Fraser University and University of Victoria

\section{Introduction}

This paper is an exploration of antipassive constructions in Halkomelem, a Central Coast Salish language of British Columbia. Data are from original fieldwork on Həlq́amin’m, the Island dialect of Halkomelem, currently spoken by around one hundred people. ${ }^{1}$ In, Halkomelem, a polysynthetic language, words usually contain several morphemes. We have been investigating the morphosyntactic properties of the over one hundred affixes in Halkomelem. This paper reports on two of these affixes, the middle suffix and the activity suffix, and their use in antipassive constructions.

Halkomelem has two different morphological means of marking antipassives. This paper explores the similarities and differences between the two antipassive constructions. Other languages of the world have been shown to have two or more antipassives. Halkomelem antipassives conform to previous generalizations about the form and function of antipassives (e.g. Foley and Van Valin 1984). However, Halkomelem shows one phenomenon that to our knowledge has never been discussed: Halkomelem allows the two antipassives to stack. We give an analysis of stacked antipassives and discuss its implications for the architecture of morphosyntactic theory.

\section{The Two Halkomelem Antipassives}

We give a transitive clause in (1a) and its antipassive counterpart in (1b). ${ }^{2}$

$$
\text { a. ni? } \text { q }^{\mathrm{w}} \partial \mathrm{l}-\partial \mathrm{t}-\partial \mathrm{s} \quad \mathrm{t}^{\theta} \partial \text { sce:łtən. }
$$

aux bake-tr-3erg det salmon

'He cooked/barbecued the salmon.'

\footnotetext{
${ }^{1}$ Many speakers have helped us with our research, but we especially acknowledge Ruby Peter, Theresa Thorne, and the late Arnold Guerin. Gerdts' research has been funded by the Jacobs Fund, the Social Sciences Humanities Research Council of Canada, and a President's Research Grant from Simon Fraser University. Hukari's research has been funded by the Social Sciences Humanities Research Council of Canada and the University of Victoria. Thanks to Aaron Broadwell, Paul Kay, Charles Ulrich, and the audience at BLS for their comments and suggestions.

${ }^{2}$ The following abbreviations are used in glossing the Halkomelem examples: $1=$ first person, 2 = second person, $3=$ third person, act $=$ activity, appl $=$ applicative, aux $=$ auxiliary, ben $=$ benefactive, comp $=$ complementizer, cont $=$ continuative, $\mathrm{cs}=$ causative, det $=$ determiner, $\mathrm{emph}$ $=$ cmphatic, erg $=$ ergative, fut $=$ future, mid $=$ middle, nom $=$ nominalizer, obj $=$ object, obl $=$ oblique, $\mathrm{pos}=$ possessive, $\mathrm{pl}=$ plural, $\mathrm{sub}=$ subject, $\mathrm{ssub}=$ subordinate subject, $\mathrm{tr}=$ transitive .
} 


\section{Gerdts and Hukari}

\section{b. ni? $\dot{q}^{\mathrm{w}} \partial \mathrm{l}-ə \mathrm{~m}$ ?ə $\mathrm{t}^{\mathrm{\theta}} \partial$ sce:łtən. aux bake-mid obl det salmon 'He cooked/barbecued the salmon.'}

The verb in the transitive clause in (1a) contains a transitive suffix $-t$, which marks controlled transitive action (Hukari 1976) and the 3rd person ergative agreement suffix. Third person absolutives are $\varnothing$-marked in main clauses. Core arguments of the verb are unmarked for case, though they are preceded by determiners signaling degree of distance from the speaker. In contrast, there is no transitive suffix on the verb in (1b); instead the middle suffix $-m\left(\sim e^{2} \partial m, \sim \partial m\right)$ appears, and the patient appears in the oblique case. ${ }^{3}$ The suffix $-m$ is used for a range of constructions, including logophoric reflexives, personal reflexives, main-clause passives, and various monadic intransitive constructions, including verbs of motion and body care. Gerdts and Hukari (1998) gives an analysis of the middle, arguing for personal reflexive as the source of this construction. Kroeber (1999) discusses the pan-Salish use of the suffix $-m$ in antipassives.

The second antipassive uses the activity suffix -els ( als). Example (2a) gives a transitive clause and $(2 b)$ gives the corresponding antipassive.

$$
\begin{aligned}
& \text { a. na?วt } \mathrm{q}^{\mathrm{w}} ə \mathrm{~s}-\mathrm{t}-ə \mathrm{~s} \\
& \text { aux go in water-tr-3erg det salted salmon } \\
& \text { 'She put the salted fish in water.' }
\end{aligned}
$$

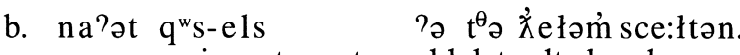
aux go in water-act obl det salted salmon

'She soaked the salted fish.'

Again, the antipassive lacks transitive marking and 3rd person ergative agreement, and the patient in the antipassive appears in the oblique case.

There seems to be very little difference in meaning between the transitive clauses and the antipassive clauses. Various person/animacy restrictions come into play, as discussed in Gerdts (1988a, 1988b). As with antipassives in many other languages, the oblique-marked object in Halkomelem antipassives is usually third person and inanimate. It can be definite or indefinite, though often it has a nonindividualized or non-specific meaning.

\subsection{Antipassive Syntax}

The two antipassives are syntactically identical. Gerdts (1998b) presents evidence that antipassives are syntactically intransitive. Causatives provide one argument for this. Causatives can be formed on intransitive bases (3), but not on transitive bases (4).

$$
\begin{aligned}
& \text { ni? cən ๆiməš-stəx }{ }^{w} \quad t^{\theta} \partial \text { swiw̉ləs. } \\
& \text { aux 1sub walk-cs+tr+3obj det boy } \\
& \text { 'I made the boy walk.' }
\end{aligned}
$$

\footnotetext{
${ }^{3}$ We use the term 'patient', without prejudice as to animacy, roughly in the sense of Dowty's (1991) proto-patient. The reader may substitute 'undergoer' or 'notional object'. Gerdts has used the terms 'initial object' and 'theme' in previous work, but we reserve the term 'theme' for locatum or entity in motion, following Jackendoff (1991) and others.
} 
(4)

$\begin{array}{lllllll}*_{n} i^{?} & \text { cən } & \dot{q}^{w} \partial 1-\partial t-s t \partial x^{w} & \text { łə słeni? } & (? \partial) & \mathrm{k}^{w} \theta ə & \text { səplil. } \\ \text { aux } & 1 \text { sub } & \text { bake-tr-cs }+ \text { tr+3obj } & \text { det woman } & \text { obl } & \text { det } & \text { bread }\end{array}$
'I had the woman bake the bread.'

Antipassives can form causatives as we see in (5) and (6); the agent of the antipassive is the object of the causative.

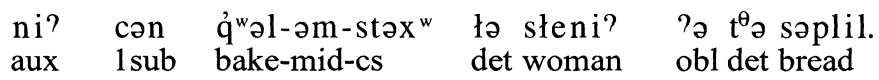

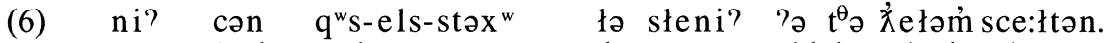

aux 1sub go in water-act-cs det woman obl det salted salmon

'I had the woman soak the salted salmon.'

As Gerdts (1988b) argues, the semantic agent of an antipassive is a surface absolutive. In terms of person agreement, Halkomelem is a split ergative language. Only 3rd person shows ergative/absolutive agreement, and only in main clauses. But there are several syntactic constructions that select absolutives, and antipassives feed these constructions. For example, Halkomelem has a constraint that a sole NP argument in a clause with only third person agreement is interpreted as an absolutive. So in the transitive clause in (7), the sole NP argument is the object.

$$
\begin{aligned}
& \text { ni? } \dot{q}^{w} \partial 1-\partial t-\partial s \text { łə słeni? } \\
& \text { aux bake-tr-3erg det woman } \\
& \text { !!'He cooked/barbecued the woman.' } \\
& \text { not: 'The woman cooked (something).' }
\end{aligned}
$$

In contrast, the sole NP in the antipassive in (8) is the subject.

$$
\begin{aligned}
& \text { ni? 'ंw } \\
& \text { aux bake-mid det woman } \\
& \text { 'The woman cooked (something).' } \\
& \text { not: !!'He cooked/barbecued the woman.' }
\end{aligned}
$$

Also, as Gerdts (1988b) notes, only absolutives link to preverbal quantifiers, and only absolutives allow their possessors to extract.

Evidence that the semantic patient is a surface "oblique object" comes from data involving extraction (Gerdts 1988b, Hukari 1976, 1979, 1980). We give a summary of extraction facts in (9). 


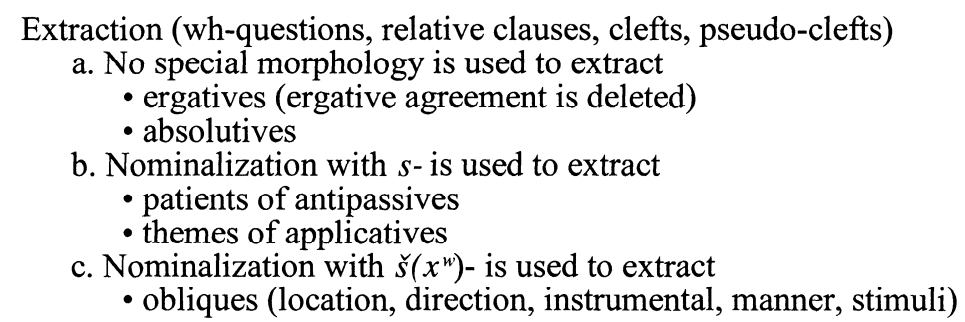

Core nominals (9a) extract with no special morphology. But oblique nominals extract via nominalization. Oblique objects $(9 \mathrm{~b})$ extract with $s$ - while true obliques (9c) extract with the prefix $\check{s}\left(x^{w}\right)$-. Examples (10) and (11) show the extraction of the patient of both types of antipassives.

$$
\begin{array}{lllll}
\text { stem } & \mathrm{k}^{\mathrm{w}} \partial & \mathrm{ni} & \mathrm{s}-\mathrm{q}^{\mathrm{w}} \mathrm{s}-\mathrm{e}^{?} \text { əm-s } & \text { łə słeni?? } \\
\text { what } & \text { det } & \text { aux } & \text { nom-go in water-mid-3pos } & \text { det woman }
\end{array}
$$

'What did the woman put in the water/soak?'

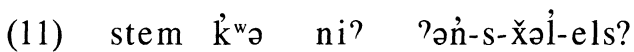

what aux aux 2pos-nom-write-act

'What did you write?'

The predicate is nominalized with the prefix $s$-. The subject of the nominalization appears as a possessor.

\subsection{Antipassive Morphology}

There are three ways to mark antipassives: - els (12a), - $m$ (12b), or Ø (12c).

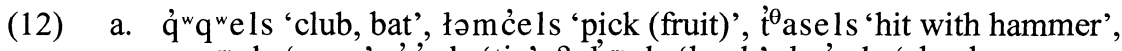

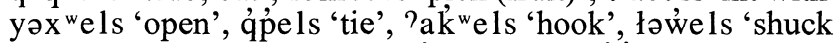

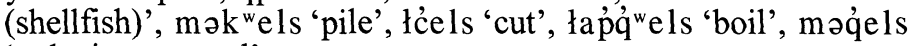
'poke into ground'

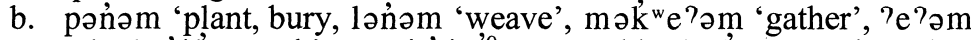

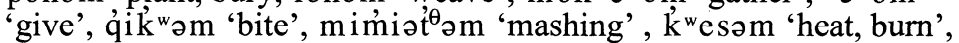
?a:m 'call for'

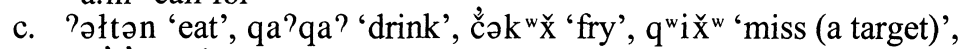
səw่q̉ 'seek'

The choice between these is basically a lexical one. -els, the activity suffix, is the most popular: approximately $90 \%$ of the verbs in our sample take -els. Only about $15 \%$ of verbs take the middle $-m$. There are around a dozen very common verbs that can form antipassives with $\varnothing$ morphology. We set aside this last class for the purposes of this paper. Some verbs allow two or three different forms. For example, we see the verb $q^{w} \partial s$ 'fall in the water' can take either the activity (13) or middle suffix (14).

(13) na? q $^{\mathrm{w}} \mathrm{s}-\mathrm{els}$

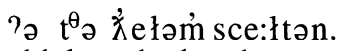

aux go in water-act obl det salted salmon

'She soaked the salted fish.' 
Multiple Antipassives in Halkomelem Salish

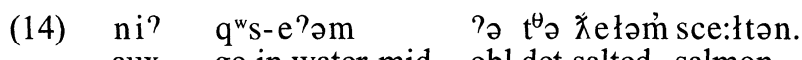

aux go in water-mid obl det salted salmon

'She soaked the salted fish.'

Some more examples are given in (15). The first column shows the verb root: the root is unaccusative with a patient-oriented meaning. The next two columns show the middle and the activity suffixes. The last column shows the corresponding transitive.

\begin{tabular}{|c|c|c|c|}
\hline root & ${ }_{-m}^{\text {middle }}$ & $\begin{array}{l}\text { activity } \\
\text {-els }\end{array}$ & $\begin{array}{l}\text { transitive } \\
-t\end{array}$ \\
\hline ' ${ }^{\text {wo }}$ 'fall in water' & $\mathrm{q}^{\mathrm{w}} \mathrm{se}$ ?om & $\begin{array}{l}q^{w} \text { sels } \\
\text { 'soak' }\end{array}$ & $\begin{array}{l}\mathrm{q}^{\mathrm{w}} \mathrm{s} \text { 't } \\
\text { 'put in water' }\end{array}$ \\
\hline $\mathrm{k}^{\mathrm{w}} \partial \nmid$ & k' ${ }^{w} e^{?}$ วm & $\mathrm{k}^{\mathrm{w}} \mathrm{kels}$ & $\mathrm{k}^{\mathrm{w}} \mathrm{ket}$ \\
\hline 'spill' & 'pou & por & 'pour it' \\
\hline ć & ćq ${ }^{\mathrm{w}} \mathrm{e}$ ? & $c^{w} q^{w}$ els & $c^{c} q^{w} a t$ \\
\hline 'pierced' & 'poke through' & 'poke through' & 'pierce it' \\
\hline & q́pe?əm & q́pels & qupat \\
\hline & 'collect' & 'collect' & 'collect it' \\
\hline
\end{tabular}

In fact, we see from an examination of a full-range of data that antipassive and transitive suffixes are closely linked. In our database of over 500 verb bases tested in combination with various suffixes and also in additional sporadic data from the Hul'qumi 'n'um' Dictionary (Hukari and Peter 1995), all verbs that can take the transitive suffix $-t$ can form an antipassive. Many stative and unergative verbs do not take $-t$, and these also do not form antipassives. Furthermore, every verb in our sample that takes antipassive $-m$ takes transitive $-t$. And verbs that take antipassive -els usually take transitive $-t$. There is one small class of exceptions to the last generalization. A dozen motion verbs that form transitives with the causative suffix - stox ${ }^{w}$ also form antipassives in $-e l s:^{4}$

(16) ?əši:ls 'paddle with something, tow', camels 'bring them up',

šq ${ }^{w} i: 1 s$ 'take across to the other side', ?ən $x^{\text {w }}$ els 'bringing to a stop',

These motion verbs are exceptional in other ways (Gerdts and Hukari 2000).

Based on these distributional facts, we conclude that, although antipassives are syntactically intransitive, they are semantically transitive. A notional object, whether stated or implied, is always part of the argument structure.

\subsection{Antipassive Semantics}

So far we have talked about ways in which the two antipassives are similar. We turn now to a way in which the two antipassives are different: they seem to have slightly different meanings. Both antipassive suffixes can be used to make the agent an absolutive. The agent is then accessible to constructions that target absolutives, as discussed in section 1.2 above. Also, both antipassives are used to express non-specific, de-individualized patients, or to avoid expressing a patient..

However, the -els activity suffix often brings an additional meaning. It is used to emphasize the action. The event is often a job-like activity that will take time and effort. Sometimes the agent is playing a role in a social situation. $\mathrm{He} / \mathrm{she}$

${ }^{4}$ Van Eijk (1997:116) has noted the same sort of small exceptional class of antipassives in Lillooet, a nearby Interior Salish languagc. 
is the delegated doer of the event. For many forms with the activity subject, certain patients are evoked even when they are not expressed. The patient is fully understood from the cultural context of the activity (see also Galloway 1993: 252-255, Hukari 1979, Suttles in prep.):

(17) q́pels 'collect' [when going around collecting money]

wan els 'throw' [when throwing out money or blankets in the bighouse]

nəw้ els 'bring in' [when showing a picture for ceremonial purposes in the bighouse]

łq́els 'lay (it) down' [when making a down payment or donating blankets] $\theta$ əyq ${ }^{w} \mathrm{els}$ 'dig' [when digging a grave for the funeral]

yəq ${ }^{w}$ els 'burn' [ritual burning of the clothes of the deceased]

pe pək ${ }^{\mathrm{w}} ə \mathrm{l}$ s 'smoking' [when smoking salmon for storing]

خəy̆gels 'push down' [when kneading bread]

yək ${ }^{\mathrm{w}} \mathrm{els}$ 'break' [when breaking old plates in ceremony for black faces]

łəw้els '(shaman) working a cure'

In various languages, antipassive is correlated with progressive or continuative aspect. For example, Blake (1987) notes that antipassive in Australian languages is often associated with imperfect, desiderative, or habitual aspect. Adams and Marlett (n.d.) note that the Madija antipassive is more likely to be used when the continuative aspect of the action is emphasized. This is not exactly what is going on in Halkomelem, since antipassives cross-cut the aspect paradigm. Perfective or progressive antipassives are allowed. Nevertheless, the job-like semantics often evoked by the suffix -els seems to be a similar phenomenon.

We can see the difference in semantics in the way the two antipassives are nominalized. Using an antipassive base to form a noun is quite common in Halkomelem. In (18), nouns formed with the $s$-prefix express a nominal that corresponds to the patient of the antipassive.

(18)

$\begin{array}{ll}\text { Noun } & \\ \text { s⿱艹̄cels } & \text { 'design, pattern' } \\ \text { sq́pels } & \text { 'collection (of money)' } \\ \text { spən่əm } & \text { 'seed, something planted' } \\ \text { stiləm } & \text { 'song' }\end{array}$

$$
\begin{aligned}
& \text { Yerb } \\
& \text { X̃cels 'make a design or pattern' } \\
& \text { qupels 'gather something' } \\
& \text { pənəom 'plant, bury' } \\
& \text { tiləm 'sing' }
\end{aligned}
$$

The activity suffix is also frequently used in instrumental nouns formed with the oblique prefix $\breve{s}\left(x^{w}\right)$-. Since the suffix -els puts a job-like cast on an event, it makes sense that it would be used to create words for tools.

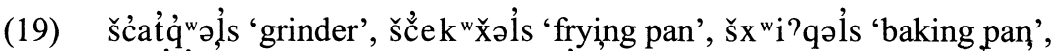
słe mcəols 'picking machine', šseq̉ols 'shake splitter', šx ${ }^{w} a x^{w} \partial k^{w} ə l s$

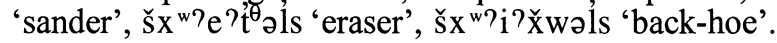

We have found no examples of the middle suffix being used in this fashion. So we find, then, that the -els suffix often adds a special job-like meaning to an event, while the middle suffix does not. 


\section{Stacked Antipassives}

The following examples show that in some cases Halkomelem allows antipassives in which both the middle suffix and the activity suffix appear.

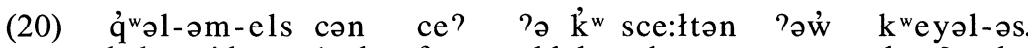
bake-mid-act 1 sub fut obl det salmon comp day-3ssub 'I am going to barbeque fish tomorrow.'

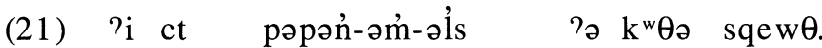
aux 1 plsub plant+cont-mid-act obl det potato 'We are doing the planting of the potatoes.'

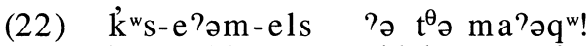
burn-mid-act obl det water fowl 'Do the job of singeing the water fowl!'

Other examples are given in (23).

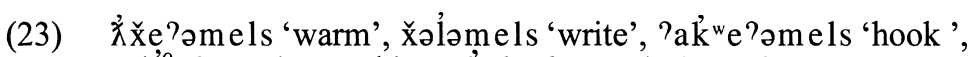
mi ${ }^{\theta} \mathrm{e}^{7}$ ?mels 'mashing', $\mathrm{k}^{\mathrm{w}} \mathrm{k}$-e? $\mathrm{em}$-els 'pour'

The opposite order of stacking - the activity suffix inside the middle suffix-is not allowed, as the data in (24) show.

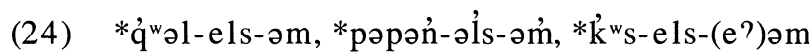

When viewed from a semantic perspective, double antipassives are not unexpected, since the two suffixes have slightly different lexical restrictions and different semantic functions. Adding - $e l s$ to a form that already has $-m$ adds the additional meaning of a job-like activity, as we see by contrasting the translation of the simple antipassive in (25) to the stacked antipassive in (26).

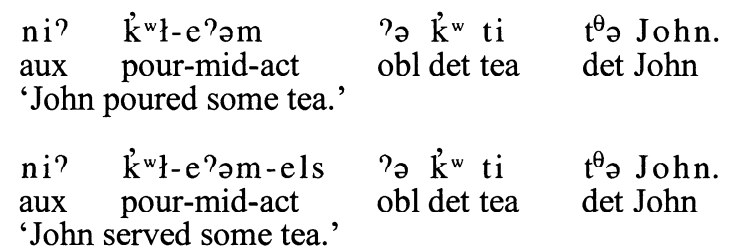

In cases like (20), the verb root takes -em ( $\dot{q}^{w} \partial l$-am)but not -els (* $\dot{q}^{w} \partial l$-els). The presence of the $-m$ makes the - els possible.

Double antipassives have exactly the same surface syntax as single antipassives. They are intransitive, as the causatives in (27) and (28) show.

(27) ni? cən qws-e?əm-els-stəx ${ }^{w}$ łə słeni? aux 1 sub go in water-mid-act-cs det woman 'I had the woman do the soaking.' 
Gerdts and Hukari

$\begin{array}{llllll}\text { (28) } & \text { ni? cən } \quad \text { x̌l-əm-els-stəx }{ }^{w} & \theta ə \text { na:s } & \text { ?ə } \theta ə-n ə & \text { pipə. } \\ \text { act 1sub write-mid-act-cs } & \text { det nurse } & \text { obl det-1pos } & \text { paper } \\ \text { 'I had the nurse fill out my form.' } & & & \end{array}$

Recall that only intransitives form causatives in Halkomelem. Also the data in (29) and (30) show that the patient in the double antipassive is an oblique object that extracts via $s$-nominalization.

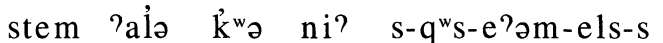
ł słeni??
what emph det aux nom-go in water-mid-act-3pos det woman 'Whatever did the woman soak?'

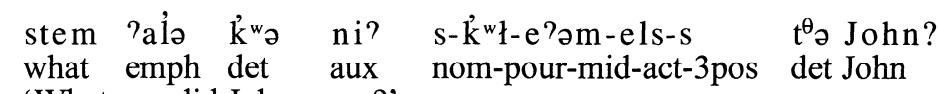

'Whatever did John serve?'

Thus, adding a second antipassive morpheme has no syntactic consequences.

Stacked -els presents a problem for the generalization we gave earlier. We said that $-e l s$ and $-m$ work like detransitivizers. They attach to transitives. But in forms like $\dot{q}^{w} \partial l$-am-els in (20), the activity suffix is attached to an intransitive base. So we seem to have a violation of our previous generalization. Actually the generalization that we need to accommodate the additional facts is quite straightforward. What -els is looking for is not a transitive base to attach to, but a verb root with a transitive argument structure. This claim is supported by evidence from lexical suffixes, the Salish equivalent to noun incorporation:

$$
\begin{aligned}
& \text { yə-k } \mathrm{k}^{\mathrm{w}} \text { ก-as-əls 'steer horses, drive car' [hold face] } \\
& \text { šašəm-a? qw-els 'smoking fish heads' [smoke-dry head] } \\
& \mathrm{k}^{\mathrm{w}} \breve{\mathrm{s}} \text {-as-els 'count money' [count round objects] } \\
& \mathrm{X}^{\mathrm{w}}-\mathrm{t}^{\theta} \partial \dot{\mathrm{q}}^{\mathrm{w}} \mathrm{-s}-\mathrm{els} \text { 'punch in face' [punch face] } \\
& \text { ?ə⿳厶-iws-els 'scrape ducks' [scrape body] } \\
& \mathrm{k}^{\mathrm{w}} \mathrm{ax}^{\mathrm{w}} \text { - } \partial \mathrm{w}^{\prime} t \mathrm{X}^{\mathrm{w}} \text { - }-2 \mathrm{ls} \quad \text { 'knock on houses' [knock building] } \\
& \mathrm{t}^{\theta} \partial \check{\mathrm{X}}^{\mathrm{w}}-\partial \mathrm{t}^{\theta} \text {-els 'washing clothes' [wash garment] }
\end{aligned}
$$

In (31) the lexical suffix is the patient. This type of lexical suffixation can result in detransitivization in Halkomelem (Gerdts 1998, Gerdts and Hinkson 1996). So, in fact, the verb base is already detransitivized when the activity suffix -els is attached. The suffix - els adds the job-like semantics. So we see that the crucial condition on -els is that it be attached to a form with a verb root with a transitive argument structure. The middle suffix $-m$ is different. Verb bases with lexical suffixes do not form antipassives with $-m$. Another use of the middle, the personal reflexive, is allowed (Gerdts to appear, Gerdts and Hukari 1998), but an antipassive use of the middle suffix following lexical suffixes is not. This, together with the fact that $-m$ cannot appear outside of $-e l s(* 24)$, shows that, unlike $-e l s,-m$ places restrictions on the base to which it attaches. We summarize the difference between $-e l s$ and $-m$ in (32).

(32) Transitivity conditions on antipassive morphology:

a. $-m$ requires the base to which it attaches to be a 2-place predicate.

b. -els requires the underlying predicate to be 2-place. 
Both antipassive morphemes require transitivity. But $-m$ requires the base to which it attaches to be transitive while -els requires the underlying predicate to be transitive.

The requirement in (32b) might seem a little strange if you are used to thinking in terms of ordered, bracketed derivation with Mirror Principle effects (Baker 1988). But having a condition on morphology that requires looking back into the argument structure of the verb root is not unprecedented for Halkomelem. Gerdts (to appear) gives the following restrictions on the two benefactive applicatives:

(33) a. Use -atc- when the underlying predicate is 2-place.

b. Use $-m e^{2}-$ when the underlying predicate is 1 -place.

Like the activity suffix, the benefactive - $2 t c$ - is attached to transitives per (32a), as exemplified in (34), but the benefactive $-m e^{7}$ - is used in intransitive contexts, as exemplified in (35).

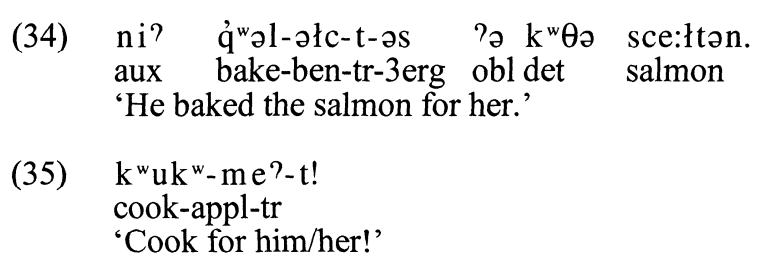

But also like the activity suffix, the benefactive can appear after lexical suffixes, as in (36) and (37). So its transitivity requirement is met by the transitivity of the root at the underlying level, not according to the base to which it attaches.

(36) $\grave{t}^{\theta} \check{\mathrm{X}}^{\mathrm{w}}-\partial \mathrm{lw} \partial \mathrm{t}-\partial \nmid c-\partial \mathrm{t}$ !

wash-clothes-ben-tr

'Wash clothes for him/her!'

(37) q’ṕ-əwəł-əłc-ət!

tie-vessel-ben-tr

'Tie up the canoe for him/her!'

We see then that the transitivity of the root can satisfy the transitivity requirement for both the Halkomelem benefactive suffix -atc- and the activity suffix -els, despite the fact that there are intervening detransitivizing suffixes.

\section{The Structure of Antipassives}

What do stacked antipassives tell us about the architecture of morphosyntactic theory? To account for antipassives, we need an analysis involving a transitive argument structure but an intransitive surface syntax. Many different analyses for antipassive constructions have been proposed in the literature. Although the terminology and devices vary across theories, they nevertheless can be grouped into two general approaches.

First, some theories take the "demotion" approach to antipassive. In these theories, antipassive morphology is associated with detransitivization. The first formal treatments of antipassive were given in Relational Grammar (Postal 1977). 


\section{Gerdts and Hukari}

The clause is assigned an initial transitive structure, but the initial object is "chomeurized" either via the retreat and advancement of the subject. Another analysis that treats antipassive as a syntactic rule is the Government/Binding Incorporation approach (Baker 1988). Antipassive morphology is base-generated as the object of the verb; the NP object is an adjunct. The morpheme head-moves to the $\mathrm{V}$ and absorbs accusative case. Other linguists have proposed non-syntactic demotion. Lexicalist approaches (e.g. Grimshaw \& Mester 1985, Farrell 1992) associate antipassive with a lexical rule affecting the argument structure of the clause, turning the object/theme into an oblique nominal. The antipassive morpheme is added to the base as a concomitant to the lexical rule.

Any of the demotion analyses can handle the simple antipassive examples. However, none of them can handle multiple antipassives. When the second antipassive is added, it should correlate with detransitivization. However, the second antipassive cannot detransitivize a structure that has already been detransitivized by the attachment of the first antipassive suffix. Thus, under demotion approaches, multiple antipassives are totally unexplained.

A second approach to antipassive has been proposed, however. Antipassive can be associated with the "maintenance" of an agent by mapping the agent, but not the patient, onto subsequent layers of morphosyntactic structure. Many functional accounts of antipassive imply this process. See, for example, "foregrounding" antipassives (Foley and Van Valin 1984) and the "agent focus" construction in Mayan (Aissen 1999 and references therein). In Mapping Theory, Gerdts $(1993,1995)$ proposes the following mapping rule:

(38) Do not link the 2 (patient) and cancel the B (object) inflectional position (if there is one).

Such a rule allows for multiple antipassive, since NOT linking the 2 twice has no more effect on the clause than NOT linking the 2 once.

In addition, a mapping analysis is possible within HPSG. Following Manning and Sag (1998) and Wechsler (1998), we propose that antipassive has a complex argument structure. The a-subject of the antipassive corresponds to the a-subject of the inner argument structure, where, by 'a-subject', we mean the leftmost argument on the (local) list.

$$
\text { antipassive ARG-ST }<\mathrm{a}_{\mathrm{i}},<\mathrm{a}_{\mathrm{i}}, \mathrm{b}>>
$$

The outer a-subject maps to the syntactic role of subject and, for Halkomelem, we assume that a (distinct) inner argument maps to oblique object. Compare this to passive (Manning and Sag 1998), roughly represented as follows:

$$
\text { passive ARG-ST }<b_{i},<a, b_{i}>>
$$

That is, the outer a-subject links to the inner a-object and this role would generally map to subject, while the inner a-subject would link to an oblique role (if at all).

If the $-m$ antipassive creates the complex argument structure in (39), then the question arises as to the structure of a double antipassive. Is it as follows?

$$
\text { double antipassive ARG-ST }<a_{i},<a_{i},<a_{i}, b>>>
$$

It is not obvious that the complex structure in (41) satisfies the condition on 
Multiple Antipassives in Halkomelem Salish

antipassives, namely that the base predicate's argument structure is transitive. It seems we need access to the inner argument structure, which is transitive.

(42) An outer antipassive [e.g. Halkomelem -els] is only possible if the AP morpheme can satisfy a condition on transitivity somewhere within its (innermost) argument structure (cf. (32b)).

Thus we see that double antipassive with no syntactic effect will be possible in an HPSG analysis, provided that the outer antipassive morpheme can satisfy its transitivity requirement from the innermost predicate.

\section{Conclusion}

In conclusion, antipassives in Halkomelem show many properties that have been attested in antipassives of other languages. One property though, stacking, is something previously unattested. Stacked antipassives are problematic for demotion analyses of antipassives. However, mapping approaches that allow for the crucial feature of an antipassive structure to be the maintenance of the agent into subsequent layers of morphosyntactic structure can accommodate multiple antipassives. We have proposed a mapping analysis within HPSG for the Halkomelem antipassive.

We might ask, why are stacked antipassives so rare? The answer, we think, lies in (32b) - the fact that the suffix - els can satisfy its requirement for transitivity from the root rather than from the base it attaches to. Such "look back" licensing runs counter to the usual procedures of ordered, bracketed derivation. We expect "look back" licensing to be rare, so likewise multiple antipassives will also be rare.

\section{References}

Adams, Patsy, and Stephen Marlett. n.d. Antipassivization in Madija. Ms., Summer Institute of Linguistics, University of North Dakota.

Aissen, Judith. 1999. Agent Focus and Inverse in Tzotzil. Language 75.3:451-485.

Baker, Mark C. 1988. Incorporation: A Theory of Grammatical Function Changing. Chicago: The University of Chicago Press.

Blake, Barry. 1987. The Grammatical Development of Australian Languages. Lingua 71:170-201.

Dowty, David. 1991. Thematic Proto-roles and Argument Selection. Language $67,547-619$.

Farrell, Patrick. 1992. Semantic Relations vs. Abstract Syntactic Relations: Evidence from Halkomelem. BLS 18, University of California, Berkeley.

Foley, William A. and Robert D. Van Valin, Jr. 1984. Functional Syntax and Universal Grammar. Cambridge: Cambridge University Press.

Galloway, Brent D. 1993. A Grammar of Upriver Halkomelem. Berkeley, California: University of California Publications in Linguistics.

Gerdts, Donna B. 1988a. A Nominal Hierarchy in Halkomelem Clausal Organization. Anthropological Linguistics, 30.1: 20-36.

Gerdts, Donna B. 1988b. Object and Absolutive in Halkomelem Salish. New York: Garland. 
Gerdts, Donna B. 1993. Mapping Halkomelem Grammatical Relations. Linguistics 31: 591-622.

Gerdts, Donna B. 1995. The A/B Parameter: A Typology of Unergatives, Passives, and Antipassives. In Proceedings of the 1995 Annual Conference of the Canadian Linguistic Association, Toronto Working Papers in Linguistics, 191-201.

Gerdts, Donna B. 1998. Incorporation. In Andrew Spencer and Arnold M. Zwicky (eds.), The Handbook of Morphology. Oxford: Basil Blackwell, 84-100.

Gerdts, Donna B. to appear. The Combinatorial Properties of Halkomelem Lexical Suffixes. $B L S 25$, University of California, Berkeley.

Gerdts, Donna B., and Mercedes Q. Hinkson. 1996. Salish Lexical Suffixes: A Case of Decategorialization. In Adele E. Goldberg, ed., Proceedings of the Conference on Conceptual Structure, Discourse, and Language, Stanford: CSLI, 163-176.

Gerdts, Donna B., and Thomas E. Hukari. 1998. Inside and Outside the Middle. Papers for the 33rd International Conference on Salish and Neighboring Languages, Seattle, Washington, 166-220.

Gerdts, Donna B., and Thomas E. Hukari. 2000. The Dual Structure of Halkomelem Motion Verbs. Workshop on American Indigenous Languages, University of California, Santa Barbara.

Grimshaw, Jane, and Ralf-Armin Mester. 1985. Complex Verb Formation in Eskimo, NLLT 3, 1-20.

Hukari, Thomas E. 1976. Transitivity in Halkomelem. ICSL 11. Seattle, Washington.

Hukari, Thomas E. 1979. Oblique Objects in Halkomelem. ICSL 14. Bellingham, 158-172.

Hukari, Thomas E. 1980. Subject and Object in Cowichan. ICSL 15. Vancouver.

Hukari, Thomas E., editor, and Ruby Peter, associate editor. 1995. Hul'qumi'n'um' Dictionary. Cowichan Tribes.

Jackendoff, Ray. 1991. Semantic Structures. Cambridge, Mass.: MIT Press.

Kroeber, Paul D. 1999. The Salish Language Family: Reconstructing Syntax. Lincoln, Nebraska: University of Nebraska Press.

Manning, Christopher D., and Ivan A. Sag. 1998. Dissociations Between Argument Structure and Grammatical Relations. In G. Webelhuth, et al. eds., Lexical and Constructional Aspects of Linguistic Explanation. CSLI, Stanford University, 63-78.

Postal, Paul. M. 1977. Antipassive in French. NELS 7.

Suttles, Wayne. In preparation. A Reference Grammar of the Musqueam Dialect of Halkomelem.

van Eijk, Jan. 1997. The Lillooet Language: Phonology, Morphology, Syntax. Vancouver, B.C.: UBC Press.

Wechsler, Stephen. 1998. HPSG, GB, and the Balinese Bind. In G. Webelhuth et al., eds. Lexical and Constructional Aspects of Linguistic Explanation. CSLI, Stanford University, 179-195.

Donna B. Gerdts

Department of Linguistics

Simon Fraser University

Burnaby, B.C., Canada V5A 1S6

gerdts@sfu.ca
Thomas E. Hukari

Department of Linguistics

University of Victoria

Victoria, B.C., Canada V8W 3P4

hukari@uvic.ca 